\title{
Leading Change: Reproductive Rights, Empowerment and Feminist Solidarity in the Dublin Bay North Repeal the 8th Campaign
}

\author{
Kate Antosik-Parsons 1*, Karen E. Till 2, Gerry Kearns ${ }^{2}$, Jack Callan ${ }^{2}$, Niamh McDonald ${ }^{3}$ \\ Published: March 1, 2022
}

\begin{abstract}
This article examines how the Dublin Bay North (DBN) Repeal the 8th activist group, an independent women-led, grassroots movement in the largest constituency in Ireland, practiced a collectivist approach to forms of 'power-with' and 'power-to' (Allen, 2018) that enabled the group to create an activist community based upon a feminist ethics of 'caring-with' (Tronto, 1993). In 2018 in Dublin, what had been a narrow majority in 1983 against abortion rights became a decisive 3:1 margin in favour. While this remarkable change can be attributed to the efforts of numerous feminist and reproductive rights activists working for many years, including those tied to the national Together for Yes campaign, less attention has been paid to new activist leaders participating at the grassroots level. This article focuses on the leadership roles adopted by first-time grassroots activists who became 'team leaders' and ran decentralised campaigns in their neighbourhoods. Using qualitative analyses of a survey of 125 members (June 2018), 16 semi-structured interviews with DBN team leaders and other key people within the campaign (October 2018 and March 2019), and the authors' own experiences, we consider how new activists recruited and empowered others to tell their stories, canvass, and lead their own actions.
\end{abstract}

Keywords: Ireland, feminist activism, reproductive rights, empowerment, leadership

It's women who are leading this, who are driving this, which in itself is fantastic. Women whose first canvass was last January $[\ldots]$ are actually leading their own groups $[\ldots]$ and they're getting the job done (Niamh McDonald, Chair of DBN Repeal, quoted in Chambers, 2018).

\section{INTRODUCTION: RESEARCHING FEMINIST LEADERSHIP}

Dublin Bay North Repeal the 8th (DBN Repeal) was steered by an independent women-led, grassroots group, established in August 2017 to repeal the 8th Amendment in the Irish Constitution ${ }^{1}$. Within about a generation, in the constituency of Dublin Bay North (DBN), the narrow-majority of people voting against abortion rights in the 1983 national referendum had changed to a vote in favour on 25 May 2018, and by a decisive 3:1 margin. The constituency of DBN had the largest voter turnout in Dublin-71.6\% compared to 65.7\% for Dublin and 64.1\% nationally - contributing the largest net of 'Yes' votes to the national total of any constituency. While there were significant and transformative local grassroots efforts across Ireland, the DBN results were striking when also considering the area's mixed housing and age profile, and average class status (compared to Dublin as a whole) (McDonald et al., 2020).

In this article, we argue that this remarkable change in popular attitudes can be attributed, in part, to the numerous grassroots activists who took leadership roles for the first time. As we describe below, 'team leaders' recruited other activists of different ages, genders and levels of experience, and empowered them to tell their stories, canvass, lead their own actions, and become involved in other forms of mutual aid and support. We

${ }^{1}$ In Ireland, the Constitution can be amended by a referendum put to the electorate. There have been 38 amendments to the Irish Constitution since it was enacted in 1937.

1 School of Social Work and Social Policy, Trinity College Dublin, IRELAND

${ }^{2}$ Department of Geography, Maynooth University, IRELAND

${ }^{3}$ Far Right Observatory, IRELAND

*Corresponding Author: kantosik@tcd.ie 
interpret the leadership practiced in DBN as exemplifying a collectivist approach to non-hierarchical forms of 'power-with' and 'power-to' (Allen, 2018) that enabled the group to create an activist community based upon a feminist ethics of 'caring-with' (Tronto, 1993). Our research fills a gap in feminist theory through our focus on the role of women as leaders in activist movements. In her encyclopaedic overview of Gender and Women's Leadership, Vetter (2010: 3) notes 'an alarming dearth of theoretical analysis of women as leaders'. Reviewing the theory and practice of feminist leadership, Batliwala (2011: 11) insists that 'the last thirty years of feminist experiments with building alternative organizational forms and leadership practices needs to be interrogated and theorized, particularly in light of the far deeper understanding of power and organizational behaviour that has emerged during this time'. This paper takes up these challenges by examining the practices of leadership within DBN Repeal through a feminist understanding of power-with.

In her summary of the relations between feminist theory and feminist activism, Amy Allen notes the importance of a relational understanding of power in feminist practice that facilitates the cultivation of capacity (power-to) and collectivism (power-with), while constraining the play of domination (power-over) (Allen, 2018). Allen's (2018) feminist critique of domination is critical of traditional notions of leadership and draws instead from the accumulated experience of feminist activism a style of politics that prioritises inclusivity, even over proximate efficiency. Her work also resonates with some historical studies of movements. Writing of black feminist activism in the United States, Radford-Hill (2000: 8) declares that the movement rejected 'the failed charismatic, phallogenic, ethically corrupt, and discredited' style of leadership produced as the norm within American political culture, and sought instead to 'raise up and support leaders who are visionary, pragmatic, inclusive, and accountable.' Such relational approaches to power recognise and attempt to create inclusive communities by addressing the barriers of external obligations that often exclude working-class women and women with caring responsibilities from political activity. In the context of the longer-term feminist campaign for reproductive rights in Ireland, we follow de Alwis (2009), arguing that our focus on grassroots forms of leadership according to power- and caring-with offers fresh thinking on what constitutes 'the political'. Following Judith Butler's discussion of grief as a psychical and physical undoing of relations with others that can lead to transformation of the self, de Alwis (2009) argues that such undoings produce spaces that empower feminists to reimagine the political. Emergent local practices empowered new and existing activists-including people who were working-class, single-parent, migrant, trans, and those with disabilities - to create spaces to tell, share, and listen to stories about their experiences of grief resulting from gender-based oppression, violence, shame, and the lack of choice in pregnancy, many of which challenged the 'good' stories about abortion highlighted by the national Together for Yes (TFY) campaign.

The intersectionality that twists gender and class together is understood as a barrier to participatory and deliberative democracy by Phillips (1996) among others. Cultivating collectivism through power-with also rests upon affective relations, referred to as the 'social erotics' or the 'libidinal constitution' of activism (Gordon, 1997; Sandoval, 2002). Feelings of belonging and being supported can also be ascribed to an ethics of care within feminist movements (Abbruzzese and Wekerle, 2011), which draw upon a history of helping women access abortion care (Kasstan and Crook, 2018). The separate moments of care identified by political theorist Joan Tronto are all evident in our account of DBN Repeal: 'caring about', 'caring for', 'giving care', 'accepting care', and collectively caringwith (Tronto, 1993, 2013). Care has also been tied to a feminist style of leadership that Naples and Bojar (2002: 383) describe as 'embracing cooperation, seeking to build alliances and relationships with care and concern for others'.

In the next section, we argue that the non-hierarchical caring and affective bonds of solidarity within DBN Repeal were established on a feminist organisational culture developed in the early months of what was then a small grassroots movement. We examine how a feminist praxis of broadly non-hierarchical leadership and care developed to include new members, some of whom were first time activists who became leaders in their own neighbourhoods. We focus upon leadership roles within DBN Repeal to discuss the skills deployed and developed by team leaders. Then we look at how activists with experience sustained and incited the activism of those with less experience. The organisational skills of the former were supported by the facility of the latter with social media. New partisans were also recruited and encouraged by witnessing strong women manage a large and growing campaign; members learned empowering feminist language from strong role models and were invited to take areas of responsibility for themselves. Following this, we turn to discuss the reception of and accommodation to leadership within the movement. In movement terms, we discuss how feminist solidarity was built through an inclusive ethics of caring-with that extended across activist experience, age, and geographical contexts.

Our research provides evidence of inter-generational practices of learning together and caring-with that forged feminist solidarities, confirming critiques of the essentialising nature of theorising feminist movements through 'waves' (O'Hara, 2021) or 'generations' (Reger, 2012). Other studies of vibrant abortion rights campaigns also emphasise inter-generational learning, including Méndez (2020: 282) who describes a young generation taking to the streets 'while demanding an inter-generational conversation around Gender Studies', and Sutton (2020: 10) who emphasises 'generational contributions, convergences, and solidarity'. Mendéz (2020) and Sutton (2020) noted 
the dynamism of a movement on the cusp of its great victory, the legalising of abortion in Argentina in December 2020. In contrast, Hall (2019: 1497) concluded that the 'absence of intergenerational dialogue and transmission of knowledge' weakened resistance to neoliberal and patriarchal attacks on women's rights in Poland.

Our article extends these discussions by drawing upon three sources of data. First, the authors were all members of DBN Repeal, working in different capacities, and we draw upon some of our personal experiences below. Of the five authors, two were in leadership. Three are self-identified cis-gender female authors, two of whom are mothers; one was elected DBN chair with extensive activist experience and one was a team leader with some activist experience but new to leadership. The third woman, an experienced activist, was new to canvassing for a national referendum, and attended DBN monthly meetings. Of the two self-identified cis-gender men, one had some activist experience and participated in information stalls only, and the other was new to both grassroots activism and canvassing; neither attended monthly meetings. With others, we created the DBN Repeal Research team, only hours after the tally of the national referendum. Some of us noted at the InterContinental Hotel celebrating our shared victory with the larger national TFY campaign that the mainstream stories of the campaign, presented at the victory celebrations in videos and published data, needed to be balanced by grassroots accounts. We wanted local members of the movement to tell their own stories and provide the voice of local leadership efforts. We also wanted to (re)claim from the TFY national campaign the research collected while canvassing our neighbourhoods, which included qualitative data (door to door information, social media data, and canvassing maps) that informs our research.

Second, we created an online survey in June 2018, answered by 125 members, followed by an informal social gathering (July 2018) in which members were invited to write responses to trigger questions. This sample undoubtedly includes some of the most committed of activists who, as the data demonstrates, had a high level of satisfaction with the movement ( $98 \%$ of respondents described their experiences with the campaign as positive). Furthermore, our survey was conducted in the euphoric wake of the success of the campaign. Nevertheless, our survey returns included more than a quarter of our DBN Repeal members when their impressions were still fresh. The surveys are a reliable guide to the attitudes towards leadership amongst those activists who were most effectively mobilised by the campaign - the ones who saw Repeal through to its successful conclusion. The remaining three-quarters of people involved with the campaign were either not reached by our online invitation or chose not to complete the survey. Some of these may have been less appreciative of the leadership strategies detailed below, and their lack of response may reflect a broader alienation from the movement and its style of leadership.

The survey results corresponded to the third element of research: in-depth interviews with team leaders and other key people within the campaign. Following the survey, we partnered with Maynooth University Department of Geography staff and students to conduct interviews. As part of feminist and public engagement research methods classes, we developed the interview questions, and co-facilitated 16 interviews, which were conducted by Masters of Arts in Geography and Final-Year undergraduate students in October 2018 and in March 2019, respectively. As we discuss below, the strategies and intentions the leaders disclosed were generally consistent with the survey findings. For purposes of anonymity, unless someone wished to be self-identified, we have assigned pseudonyms for those interviewed.

\section{POWER-WITH: FEMINIST LEADERSHIP}

Repeal was a cause that women led. In this section, we describe how feminist governance systems were developed within DBN Repeal. Participatory democracy, including consensus and inclusion, was adopted as a guiding principle. There was a fervent belief in addressing any obstacles to women's participation in the movement, including styles of male domination such as described by Allen (2018). Furthermore, as an ethical stance, care and mutual respect shaped the affective relations within DBN Repeal. Following a brief overview of DBN Repeal, we describe the way activists addressed these values and the manner in which they reflected upon them after the conclusion of the campaign. We consider cultures of feminist leadership in DBN by discussing the organisation and power relations of the group, how leadership roles evolved, and the skills learned by leaders and members who actively participated in the campaign.

At the peak of the campaign, the DBN group counted between 400 and 500 supporters based upon our tally in May 2018 of participants in our private Facebook members page and WhatsApp canvassing groups ${ }^{2}$. Our voluntary survey of 125 members indicated that $80 \%$ were women. For many (about $43 \%$ of respondents), this was their first political experience. Such a profile, however, could not have been predicted when the group first formed.

${ }^{2}$ Social media utilised by DBN included public and private Facebook pages; and Twitter, Instagram, and WhatsApp accounts. 
Challenging the then-governing Fine Gael's stance on the 8th Amendment, in April 2017, 64\% of the Citizens' Assembly advised not having a restriction on abortion in the Irish constitution, prompting activists to organise a local campaign to secure this. The first few monthly meetings of what became DBN Repeal (August 2017) included between 10 and 20 people. Many of those women had previous experience in politics and/or activism, and used their experience of political activity, including their feminist distrust of hierarchical relations of domination, to craft the power-with more inclusive relations that underpinned DBN Repeal. Two experienced DBN activists, Brian and Carol, who were also involved in the 1983 anti-amendment campaign described DBN Repeal as a 'bottom up' campaign, noting that the group organically developed into a major campaigning force because of the efforts by the women leaders. Similarly, the DBN chair Niamh McDonald, one of the authors, acknowledged the importance of its members in leading a grassroots campaign.

As a newly formed grassroots group, the early part of the campaign had a rather fluid approach to coordination. Experienced female activists ran monthly (and later biweekly) meetings, and used what Niamh described as a 'lighthanded approach towards facilitation'. Donations collected at the end of meetings went toward the cost of room hire in a local community centre, and, later, towards other campaigning activities. The group evolved to include three elected officers (chair, secretary, treasurer), eighteen team leaders and members, but maintained inclusive organisational structures based upon feminist activist models of leadership that recruited new members to become involved in locally-based activism quickly and easily. The elected officers all had previous activist experience in running political campaigns. Two were self-identified members of a political party, and the chair of DBN was at that stage unaffiliated. Reflecting upon her role as chair, Niamh saw herself as facilitating spaces for people to engage whilst also focusing on the logistical and planning aspects of the campaign. She needed to be 'always in the future never in the now' to plan for the next phases of the campaign. Another DBN officer noted:

[1]t was very wise that we set up so early because we had the structures in place well ahead of the campaign. So, we could go right into canvassing [and] we covered the whole constituency—and it's a big constituency. And so it was just as well that we had [that] in place (Carol).

By January 2018, a constitution was drafted to set up a bank account to comply with the Standards in Public Office Commission (SIPO) regulations.

The power relations of the DBN leadership were envisaged to be horizontal rather than hierarchical. At larger DBN meetings, minute-taking rotated and decisions were put to the floor and decided by vote. Meetings were largely given over to discussion, debate, and the airing of different perspectives, including dissent. One survey respondent was unhappy with the nature of internal debate: 'While people were encouraged to speak, it very much felt like the outcome of any discussion was predetermined' (DBN.06.18.126) ${ }^{3}$. This was the only respondent who, in answering a question about barriers to their involvement with the group, was at all critical of the openness of discussion within DBN Repeal. Most decisions were made collectively, meaning that everyone attending agreed, although a handful of the most contentious issues were decided by majority vote. All members were invited to brainstorm collectively, come up with ideas, and then enact actions for change, rather than to follow directions passively from those in charge. Additionally, people volunteered or were encouraged to take roles to get tasks done. DBN Repeal leaders also modelled anti-sexist, anti-racist, anti-ageist, anti-ableist approaches and language, while nurturing gender, class, age, and sexuality inclusivity at meetings. Difficult conversations and complex political nuance were confronted, including the debate about whether the group should maintain its independence from TFY, discussed in more detail below. Legal, trans activist, and other experts in the group were invited to share information and provoke discussion; guests were invited to contribute to our shared dialogue. Though some first-time activists may have had reservations about initially becoming involved, for most this reticence soon dissipated. One member who became a team leader said:

The initial contact that I had with it [the DBN group] was that this (...) was going to be (...) 'run-by groups'. As it turns out, it became an absolute, totally people-driven, normal, normal-people driven kind of force (Noreen).

Another member who became centrally involved in the campaign said:

I went in not really with many expectations. I wasn't sure what to think when I walked in the room [at my first meeting]. There was a lot of people that already seemed to know each other and so I wasn't really sure where I would fit into the group (...) but very quickly I felt welcome (Anna).

\footnotetext{
${ }^{3}$ Survey responses are identified by a date and respondent number.
} 
A mutual form of learning between leaders and members ensued, supporting a form of feminist solidarity, to which we return below. The culture of solidarity and mutual support, as led by strong women, fostered inclusivity, creativity and confidence.

The activities of the group changed as the campaign developed and as DBN Repeal grew. Roles established by campaign and team leaders encouraged members to 'own' the campaign. Leaders within DBN Repeal were the local activists who put 'structures in place' to facilitate a large number of volunteers to engage with, participate in, and contribute to the success of the DBN campaign (Niamh). Volunteers expressed their motivation in terms very similar to what Tronto (2013) describes as moving from caring about an issue to caring for an issue, which means taking responsibility leading to action. As one member expressed, she wanted to 'do something more than just being at home on the computer talking about it' (quoted in Chambers, 2018). Attendees volunteered for or were invited into different tasks which drew upon an individual's expertise and/or interest, including: presenting information on different topics; organising action items, such as holding a small event to mark the anniversary of the death of Savita Halappanavar; circulating images of actions on Facebook; joining and reporting on the national Coalition to Repeal the 8th; volunteering to work the first stalls; and training members to work at information stalls and to canvass (McDonald et al., 2020). Members willing to take on more responsibility for the logistical aspects of the campaign were encouraged to do so. By dedicating their time, knowledge, energy and enthusiasm, activists who were leaders invited, even inspired, others to participate.

The DBN chair identified the first group canvass held in January 2018 as the key moment when a new set of DBN members took charge in organising the campaign:

That night the women came down: they went out, they canvassed. They broke through the fear of talking about abortion to Irish people at the door. They went on to lead the campaign. They had never done any activism before and that is the thing you wanted to achieve (...) to have a core group of radicalinclusive feminists in an area who are able to organise and win a campaign (Niamh).

As noted above, many of this 'core group of radical-inclusive feminists' were first-time canvassers. They also later played an important role in organising and facilitating DBN's first open public meeting in Le Chéile Community Centre in Donnycarney in March 2018, where the group's monthly meetings were also held. In advance of the meeting, active members living in different areas of the constituency agreed to be available to meet interested attendees. At the meeting, signs with neighbourhood names were posted around the room to encourage people to register availability within their locality. $\mathrm{DBN}$ is a large and class-diverse constituency. More affluent neighbourhoods include villas on Griffith Avenue, the city's first planned suburb of Marino in the north-west, the stately terraces of Clontarf in the south, and the architectural jewels of Howth in the east. Middle- to working-class areas include modest cottages in Raheny, bedsits and apartments in Coolock, and areas of social housing in Darndale, Edenmore, and Kilbarrack (the latter of which are slightly below the city average for local authority housing) (McDonald et al., 2020: 125). Rather than being overwhelmed by a big room, the signs meant that people might recognise their neighbours and feel more comfortable about participating. Our most active members also circulated to answer questions, assuage fears and encourage involvement.

Some DBN activists subsequently took on higher levels of responsibility. They became referred to as 'team leaders' for a neighbourhood because they supported members in participating in canvassing, leafletting, wo/manning information stalls and visual displays, and fundraising, but also in what Tronto calls giving care and receiving care, which included providing emotional support, co-ordinating financial support or baby/elder-sitting for those with these obligations. Of the eighteen team leaders in the group, nine were parents, and six were mothers with young children. Giving and receiving care were vital. Many of these women had to balance their parental responsibilities with their commitments to the campaign. As one explained:

Most challenging was probably the time [commitment required for the campaign], and [...] having to take so much time away from my normal activities and my home and whatever childcare responsibilities [I had]. [...] And sometimes there was a lot of pressure you put on yourself, and probably commitments you took [on for the campaign], that you [were] going: 'Am I going to be able to manage this?' (Ellen).

First time activists who became team leaders were often paired with those with previous political experience, which enabled knowledge sharing (McDonald et al., 2020). For example, the team leader for the large workingclass district of Coolock, and one of our authors, was a US-born mother of four children who was new to leadership. From March to May 2018, she managed two evening canvassing events and one half-day weekend stall each week in her area. She was paired with another team leader, a Dublin city councillor with a decade's political experience in the area. The councillor utilised his knowledge to advise the best ways to canvass the area. In addition to coordinating canvasses and stalls, this team leader stored and distributed the materials for these events in her 




Figure 1. Dublin Bay North Repeal the 8th, Leaflets, Badges, and High Visibility Vest. Photograph: K. AntosikParsons. Used with permission.

house (including high-vis jackets, clipboards, tally sheets and flyers) (see Figure 1). She later collected and managed leaflet and poster deliveries from the national TFY campaign for distribution to DBN team leaders.

In addition to DBN officers and team leaders, other roles important to our group included the social media team and merchandising. Three DBN members were responsible for managing our public and private Facebook pages, and the Twitter, Instagram and WhatsApp accounts. They also worked constantly to reply to new queries, put out relevant and interesting content, and share messages. When the canvassing started, pictures taken were sent to the social media team to post. There was considerable overlap between DBN officers, team leaders, and the social media team, which was important because experienced members could reassure new joiners of the days and times when they could attend a canvass, and provide people with a personal point of contact on the day.

The merchandise was an important fundraising mechanism for the group and it enabled the group to be financially independent from the TFY national campaign. The merchandise person strategically printed and marketed $\mathrm{T}$-shirts and badges. She linked in with a $\mathrm{T}$-shirt company from which her partner had previously sourced football jerseys. Using her ingenuity, she marketed a batch of misprinted shirts, for which the group were not charged due to the error, as 'once off T-s: the demand for these was high. She independently purchased a badgemaking machine, and her bespoke badges were widely and freely distributed within the constituency and later nationally, when other groups put in requests for specialty badges. This 'pay-it-forward' attitude enabled other groups to use the badges for their own local fundraising, a quality characteristic of the collective and generous spirit of the campaign. A small-batch production of a 'Kates Together for Yes' badges even captured the imagination of then Fine Gael TD Kate O'Connell who sported hers proudly. DBN officers were in awe of the fundraising:

[M]ost campaigns that I've been involved in always end with a deficit-we're out of money, we don't have enough money. This one was the reverse, we made a constant stream of money on fundraising through T-shirts. And people identified with the local Dublin Bay North T-shirt! (Carol).

DBN merchandise also functioned as a visible marker of the local DBN Repeal community.

DBN leaders deployed many talents. Interpersonal skills, or 'people skills' as one leader called it, included building confidence (for members as well as leaders), creating an inclusive space for people to become involved, developing clear communication and language skills, and learning to listen. As one team leader noted:

I think it was really important to $[\ldots]$ be very personally welcoming to them [new members] and try and build that one-on-one relationship with everybody on the team (Maeve).

The social media team also worked tirelessly to make DBN Repeal seem friendly, responsive and engaging. The immediate welcoming and personal contact made with new members was critical, for, from the genesis of the group and throughout the campaign, DBN Repeal leaders were determined to add members. Growing the campaign meant that people from local communities would become empowered to make meaningful change in their city and society; it also meant more 'feet on the street,' enabling the group to cover the entire constituency with canvassing and public events. 
Multiple interpersonal benefits accrued for all members when canvassing. While door-to-door canvassing, known as 'ground campaign,' has long been employed in local and national elections in Ireland, it was not typically a feature of referendum campaigns until the Marriage Equality Referendum (2015) (Elkink et al., 2017). The act of asking strangers and/or neighbours their views on a controversial topic required respect and empathetic listening, again a form of giving care. This was often a scary experience for first-time canvassers. One team leader said she tried to:

Just make people feel comfortable. Give them the information and hopefully the confidence to then go and do more (Hannah).

Even experienced campaigners gained new skills:

I think I would have definitely improved my listening skills because it was different to political canvassing in a sense. I think there were more stories at the doors, there were even arguments at the doors (Siobhán).

Approaching neighbours who held strong beliefs meant also learning to accept a diversity of views. As one team leader recalled:

You had to remain incredibly calm, even when one of your neighbours is chasing you down the street.

$[\ldots]$ There was one particular occasion where we had a man run down the street at two of our canvassers

[...]. In those situations, you needed to be able to defuse it (Noreen).

Leaders also described having to be 'emotionally supportive' of their teams, particularly when canvassing situations were challenging.

A skill that many experienced team leaders learned was being respectful of all members' needs, which meant for one person: 'to give everybody space' (Brian). When considered in terms of the larger group's models of leadership defined above, this form of responsible feminist ethics meant creating spaces that were open and inclusive. For the same team leader:

You don't have to direct everything. And everybody's opinion and views are as important in a campaign like this (Brian).

Another team leader reflected that they learned to read a room at the meetings, maintaining an awareness of those who may have been quieter and checking in with them afterwards. For yet another team leader, it was critical to make it

$[\ldots]$ as easy as possible for people to link in with process, both to participate and feel that they had a share in it (Anna).

DBN members and leaders also gained experience and confidence in professional organisational skills, including coordinating large groups, managing time effectively, and using social media as an organising tool. Indeed, as one team leader noted:

one of the reasons why they're [new members] likely to come back is because of the professionalism and the organisation of the team leaders (Eoin).

Members developed their communication and technical skills as part of the social media team while advancing the DBN campaign. They identified and linked in with the online presence of activists to ensure DBN Repeal tweets reached large audiences. The team kept up to date with the developments of national and local campaigns, making DBN tweets relevant by scanning a vast number of online media sources to condense ideas down into a 280character Tweet (Anna). The DBN WhatsApp group enabled information to be shared quickly and allowed team leaders to make key decisions about organising canvasses, information stalls, and other activities in their locales.

Team leaders also gained transferrable skills, learning how to communicate with members within one's neighbourhoods, managed primarily through WhatsApp, but also through private text messages or phone calls for members not on social media. Though it could be time consuming to personally respond to every question about logistics or messaging, leaders did so to ensure that each person felt looked after:

There was so many new people coming in, some through WhatsApp actually, for the first time- that was an extra job for those people [social media and team leaders] actually. Because if somebody new asked a question and is not responded to they might take that personally; they might feel like they [DBN] don't care. They might think they asked a stupid question or something like that. [...] I don't know if you can quantify that, just how much time those group leaders spent looking after that aspect of 
organising the campaign at a local level. But it was crucial to the campaign in terms of the functioning of the local groups (Eoin).

Ultimately, creating supportive spaces for its members was the most powerful practice in building confidence and trust amongst its members. We now turn to the ways that DBN leaders encouraged the participation of members.

\section{CARING-WITH: FEMINIST SOLIDARITY}

Creating inclusive spaces of care, empowerment and support fostered solidarity as a potent affective force in DBN Repeal. There are many potential bases for solidarity within feminist movements. Sisterhood has served as a powerful collective identification in many contexts (Fox-Genovese, 1991), despite critiques of essentialism (Willis, 2012). Writing of leadership within feminist movements, Hyde (2018) suggests that a belief in the collective can be felt as an almost mystical or magical sense of solidarity, or a 'collective charisma'. Yet there was relatively little explicit evocation of sisterhood in the survey responses and interviews, perhaps because it may have been implicit. However, the movement for abortion rights, while led by women, welcomed men into its activism which was defined by bridging (Petray, 2010). Solidarity in this way rested upon empathy with those most immediately affected. As in other activist movements, empathy mobilises the energies of others and, in turn, supports those most in need as they make public demands for redress. Santos (2020) suggests that empathy and solidarity are mutually nourished in a politics of care. Indeed, as DBN Repeal activists testified, the movement embodied trust, respect, plurality, and solidarity very much in the manner of Tronto's (2013) notion of caring-with.

In this section, then, we consider how feminist forms of caring-with built an inclusive feeling of feminist solidarity for DBN members across their differences of age, activist experience, and residence. Most of our 400500 volunteers joined in mid-May 2018, many who had no prior experience of activism, and yet the referendum fell only weeks later. As suggested above, key tasks assumed by leadership included integrating, sustaining and informing the new volunteers. Creating an ethics of caring-with others also resulted from DBN leaders' ability to instil confidence, create inclusive spaces for members and strangers, and support on-the-ground experiential learning, what we describe elsewhere as a feminist pedagogy (McDonald et al., 2020).

Leaders instilled confidence in a number of ways. For many first-time activists, the prospect of cold-calling at a stranger's home or working an information stall to discuss what, for some, is a very contentious issue, was daunting. Team leaders were keenly aware of this, many of them having been in a similar position only months previously. To introduce new members to canvassing, DBN used a 'buddy system' which paired newer volunteers with more experienced members (McDonald et al., 2020). Team leaders paired individuals in female/female or female/male teams and would direct this process as a form of caring for the new recruit:

You need to buddy them up, be very straightforward and talk to them after and ask 'Would you feel like coming back, how did you find that, were there any issues?', and buddy them up with someone that would be experienced. It's all about the new person (Niamh).

Before each canvass, team leaders would also hold a briefing to instigate discussion of topical issues or typical questions that had arisen on recent canvasses. Team leaders gave encouragement at the outset of the canvass, reminding people that they didn't need to know everything and could call on them by phone for assistance if needed.

While canvassing, team leaders often fulfilled an organisational role, making sure everybody was safe and not too far behind, marking off areas covered, keeping late arrivals updated through WhatsApp, and ensuring there were enough materials to go around. As one member reflected:

There was a lot to do around getting people enthusiastic, being clear about what we needed people to do. I felt that as a team leader my job was to be an organiser, to make my area the type of place where people who wanted to be involved could step in and participate (Anna).

Here we see that giving confidence to new members meant not only encouraging people, but making sure canvassers had a clear message. The success of team leaders and the campaign in instilling confidence can be seen from the results of our survey of members conducted in June 2018. Of respondents who canvassed, $68 \%$ were first-time canvassers and yet $95 \%$ of respondents had confidence in the facts and arguments while canvassing. This is quite an extraordinary achievement given that the majority of team leaders were themselves first-time activists with only a couple of months more experience than those they were now integrating into the movement.

Team leaders coordinated organisation and logistics at the neighbourhood scale through WhatsApp chats, smaller pre- and post-canvass discussions, and in public while campaigning. In all of these settings, team leaders created inclusive spaces for dialogue and mutual support. For example, WhatsApp became spaces to ask questions 
at constituency and neighbourhood levels. While primarily used as a vital tool for organising by team leaders, neighbourhood WhatsApp groups offered separate discussion chats not directly related to campaign activities for all members. People used this social media platform to share the times and places of local activities, gauge numbers of attendees, live track during canvasses, provide feedback, and reach consensus on issues as they were happening. This level of support made it easy for people to try out an activity and gain confidence, which led to enthusiastic participation. These positive experiences empowered members to return and try out new forms of activism. The group's larger monthly meetings described earlier were open to all members, and team leaders encouraged people they got to know in their neighbourhoods to attend these personally. Our survey shows that the significant majority of people who attended meetings felt involved in decision making, with ideas and concerns listened to and discussed. Members who indicated they did not feel part of decision making were predominantly very late joiners, and most acknowledged being happy to follow the lead of experienced members (McDonald et al., 2020).

Canvassing was an activity highly valued by DBN members. The organisation of the canvass was central to creating ethical spaces of dialogue. The horizontal leadership culture within DBN Repeal established the value of building egalitarian spaces of communication and learning locally. Pre-canvass briefings and post-canvass debriefs fostered supportive face-to-face discussions. While prior briefings were important to keep people up-to-date and to address concerns, debriefs gave people a chance to decompress and talk through their own experiences. One member replied to our survey that canvassing was 'thought out and thorough'; another remarked that 'the canvass leads were well-organised, inspiring and motivational' (DBN.06.18.86, DBN.06.18.05). While canvassing was bookended by briefings and discussion, spaces of encouragement and support were threaded throughout and mobile. Often team leaders checked in with members throughout a canvass, offering support and encouragement if someone had been at a difficult door. Inclusivity and care on the canvass were often remarked upon in our survey. One respondent referred to the 'kindness and patience shown to us who were first-timers,' and another reflected that they only 'got involved toward the end [yet] still felt extremely valued' (DBN.06.18.86, DBN.06.18.36). The feminist ethic of care also extended to the people being canvassed:

The areas I worked in were very densely populated which meant that you had doors that were side-byside, so we never canvassed these doors at the same time. To give people that little bit of space (...) people are talking about sensitive issues (Noreen).

This approach, together with the buddy system, can be thought of as learning by doing or experiential learning. Giving people space for strangers to share their stories also drew upon the approach of campaigners from the previous Marriage Equality referendum in a manner of 'affective vulnerability' (Fischer 2020: 985). DBN members also shared and listened to personal stories while canvassing:

I suppose sometimes I would have a knot in my stomach around sharing personal information about myself, but there were times where I felt really empowered after doing it and I would feel like I had a connection with someone. When I began to open myself up people would tell me their stories. And that was really powerful for me, particularly when I would knock on someone's door and someone would tell me either their abortion story or a story about adoption, marital rape, domestic violence; these things that I hadn’t expected to be told. (...) It was just so much more than just about the Eighth Amendment, which was really overwhelming for me sometimes (Anna).

Unpredictable encounters epitomised the dialogic, participatory and experiential learning that was central to the DBN campaign, a feminist pedagogy facilitated by team leaders (McDonald et al., 2020). As we have argued elsewhere, generating knowledge through conversation, both with each other and with people at their doors, is a form of empowering feminist pedagogy (McDonald et al., 2020). The self-confidence built during canvassing was created through relations of mutual trust and care: reliance on team leaders to coordinate actions in their neighbourhoods, confidence in fellow members' ability to canvass with respect, and care and support for each other and strangers. Team leaders facilitated these relations and led by example. In another form of giving care, this team leader also directed people canvassed to counselling organisations like the Irish Family Planning Association if they became distressed about issues arising from their own experiences. Moreover, emotions causing discomfort may be useful in generating new and co-constituted knowledge, especially when vulnerabilities are acknowledged and shared with others (Pileggi et al., 2015). Giving care and accepting care anticipate a new way of making society, and Tronto's (2013) caring-with presages a social order quite different to the patriarchal hierarchies from which feminist praxis strains to keep its distance. The radical potential of accepting care for a praxis of caringwith is numinous in the account of one team leader who had developed the confidence to tell her own story while canvassing:

Being in the position that I was in as a person who has had an abortion, I was sharing my own personal story [at the] doors. And when I first started canvassing, I was really hesitant to do that but (...) I decided 
that it was really important for me to talk about my personal experience with people. Because I knew that destigmatising it and saying, 'Hey I'm a woman who has had an abortion and it's a normal thing, people make this choice, you know lots of people do and it's nothing to be scared about!' was really important for me (Anna).

This example illustrates how the DBN campaign went beyond the national campaign's emphasis on abortion as 'safe, and rare,' insisting instead, as Cullen and Korolczuk (2019: 16) propose, that abortion must 'be accepted as a commonplace, essential and life-giving decision for all who choose it'.

In relaying another story, this same team leader described a situation in which she was supported by her colleagues. Seeing some new volunteers engaged in a heated debate at an information stall, she approached and sought to engage empathetically by telling her own story. However, the hostility grew and as she withdrew, the DBN members she had given care to reciprocated:

The six other people that I was with formed this circle around me, and the level of support that they gave me was amazing. And I remember several of them coming over [and asking me], 'Are you ok?', hugging me. You know [telling me to] 'Take a couple of deep breaths', [and] 'It's O.K' and [pause]—it was this amazing exchange that we had. I had stepped forward to protect them in a sense, but then afterwards, they were protecting me (Anna).

Mutual relations of giving and accepting care are the basis of caring-with, the affective basis of a profound movement culture.

\section{POWER-TO: FEMINIST AGENCY AND PARTICIPATORY DEMOCRACY}

In her overview of participatory democracy, Polletta (2002) finds that the affective roots of trust, respect, and caring can license informality and exclusivity. Informality can confine power within a friendship circle and exclusivity means that groups often fail to move beyond the circle of association or friendship upon which they were founded. A study of Occupy Pittsburgh reported similar findings and underlined the tendency of open meetings to favour the most vocal and belligerent, often at the expense of those marginalised for whose interest the movement declared itself (Smith and Glidden, 2012). In this section, we review the extent to which the exercise of leadership and power within DBN Repeal courted the risks identified by Polletta (2002) and by Smith and Glidden (2012), while considering how feminist leadership functions as capacity (power-to) rather than coercion, 'as energy and competence rather than dominance' (Hartsock, 1983: 224). Studies of activist engagement stress the importance of egalitarian and participatory structures that 'encourage the continued involvement of members' (Bunnage, 2014: 435). Effective leadership sustains 'the agency of other participants' (Morris and Staggenborg, 2004: 174), but for feminists, this agency is not only individual but also collective.

Almost all (98\%) survey respondents looked back on their time with DBN Repeal as a positive experience. Elaborating upon their answer, several referred to the group as inclusive and efficient. One said that the campaign 'was run with honesty and with integrity,' while another described the leadership as 'incredibly effective' (DBN.06.18.19, DBN.06.18.76). Participatory democracy imposes its own constraints and one member

found the need for consensus on every little thing frustrating and slowed momentum, especially at the start, but I know that's how these groups have to work (DBN.06.18.62).

Several noted nonetheless that effective leadership allowed inclusion. DBN Repeal was 'very organised at the top, but dedicated to hearing out other members (which could be [...] loud)' (DBN.06.18.104). Not every member chose to engage with decision making but many still felt they gave their consent:

There was strong consistent leadership and direction but I felt it was democratic and was never forced to do anything at all. I was not involved in major decision making but on the things I worked on I was given the necessary freedoms (DBN.06.18.06).

Some noted the ease with which they could drop in on different DBN actions and still feel a part of the collective group: 'I was informed of what was happening on a daily basis and could choose when I could participate' (DBN.06.18.101).

The feminist culture of sharing power within the group was important for members and that the style of leadership was acknowledged by survey respondents, regardless of experience. Inclusivity was vital and in this sense DBN Repeal exemplified Dewan's (2010) observation about a coherent 'movement activism' in Irish feminism defined by shared goals. In contrast so-called 'waves' of feminist activity are associated more with expressing a singular identity. As one DBN Repeal member commented, it was 'incredible that such a traditionally disparate 
group came together and achieved so much positive work' (DBN.06.18.47). Certainly, there was tremendous diversity within the group, including, as noted above, many young people in their first political campaign (Holborow, 2018a). Yet even experienced activists recognised DBN Repeal as special, as 'one of the best organised grassroots campaigns that I've been involved in 26 years of political activity' (DBN.06.18.103). The transformation of people through their engagement in the movement did not mean burying prior differences in a common cause. One member said that DBN Repeal 'probably changed my life in that I don't think I'll ever not be an activist now' (Maeve). Another said that they were 'absolutely transformed,' gaining 'so much confidence to be able to deal with different things' (Noreen). In the survey, another member said that it was one of the 'most uplifting, engaging, reassuring, educating experiences of my life,' and that the leadership team was 'polite, friendly, inclusive and encouraging' and 'could not have made the campaign any easier' (DBN.06.18.56). Another member, described this culture of feminist solidarity and the personal transformations it produced in this way:

I have been involved in many campaigns but I have seldom encountered such enthusiasm, energy, and spontaneous capacity for organisation. Everybody literally lent all their talents and imagination towards making our work effective. Newcomers were quickly integrated - partly because they were required to canvass and that meant immediately putting themselves forward on the doorstep as spokespeople for the campaign. Everyone's political development literally took off and the result was a strong group of people united around a pressing cause (DBN.06.18.66).

The political development of the group and its commitment to inclusivity developed the culture of caring-with while grounding the group's sense of solidarity, self-confidence and autonomy. Kennedy (2015), co-founder of the umbrella organisation The Coalition to Repeal the 8th, formed in the months following the Protection of Life During Pregnancy Act (2013), correctly anticipated that the efforts of a large-scale grassroots movement would be necessary to legalise abortion and regulate it like other models of women's reproductive health care. DBN Repeal was an early response to her call for grassroots' organisations, established already in August 2017. While there were a range of types of feminist strategies in the local activist groups across the island, DBN was situated closer to the feminist activist end of the continuum identified by Connolly (2020: 51) as those 'preferring direct action' and what de Alwis (2009: 87) describes as a 'politics of refusal'. In contrast, liberal feminists at the other end of the spectrum worked 'closely with the Fine Gael-led government, establishment obstetricians and even celebrities', and included the new TFY national campaign, launched in March 2018 (Connolly, 2020: 51). Despite the encouragement of the Citizen's Assembly's conclusions the previous year, the national campaign followed a 'politics of request' (de Alwis, 2009: 87) that highlighted a white, middle-class strategy of respectability modelled closely on the earlier national Marriage Equality campaign. To the activists of DBN Repeal, it appeared that TFY was addressing the most cautious among those who might be persuaded to accept some sort of gradualist reform of Ireland's abortion laws, shifting the discursive focus of the abortion debate "from "choice" to "needs"; from "rights" to "healthcare", and from judgement to empathy and compassion' (Barron, 2019: n.p.). The stories and language of TFY also highlighted 'good' abortions, such as heteronormative parents' decisions to terminate pregnancy in cases of fatal and severe foetal anomaly, rather than including the range of reasons, stories and voices for those seeking choice and reproductive rights, including working-class, trans and migrant women, and sex workers (Niamh).

After intense debate, DBN Repeal chose to maintain its independence from the national campaign. The comprise solution was to affiliate with the national campaign, but for DBN Repeal to retain its name and separate identity. Maintaining our organisational and financial autonomy enabled us to produce our own posters and leaflets, using our own words, stories and messaging. By this time, DBN Repeal had spent more than a half-a-year campaigning on a more radical platform that refused to stigmatise women who sought abortions for socioeconomic reasons (Enright, 2018; Taylor et al., 2020). Experienced DBN Repeal activist Marnie Holborow (2018b: 45) disputed the need to accede to the strategy of having a tightly controlled message, arguing that the mass campaign had 'hundreds of activists only too aware why they are for Repeal and these activists are getting live feedback on the doorsteps and on the streets'. One of the authors remembers the group meeting at which officers asked how DBN wanted to respond as a group. The TFY message felt, to them, like a slap in the face, as though all the decades of feminist activist work, including their work now, was being forgotten in an abundance of caution. The very group claiming to speak for women seemingly now had little faith in the central message relayed by all the local and grassroots activists: 'Trust Women'. Proudly wearing DBN Repeal badges and hoodies stating 'A Woman's Place is in the Revolution'-challenging the Irish Constitution's framing of a woman's place as in the home-members rejected TFY's focus-group constructed messages of sympathy and limited change, and instead raised funds to print our own leaflets and posters that proudly included words like 'CHOICE' on them. The diluted TFY message seemed contrary to the inclusivity of caring-with as developed within our community of activists. It also felt like a concession to the Catholic Church's denigration of women's bodily autonomy (Fischer, 2019). One study of debates on the message boards of Irish national newspapers showed that some Catholics can reconcile a right to abortion with their personal faith (Sambaraju et al., 2018). However, the official position of the Church is 
hostile. Negotiating access to 'a defensive, almost apologetic endorsement of abortion' (Ralph, 2021: n.p.) acceptable to the majority of practising Catholics might prepare the way for a service that fell far short of the demands made by generations of feminist activists.

DBN Repeal members had the confidence and solidarity to stand apart from the national movement when the stakes could not have been higher. The group saw TFY as a campaign that mobilised women but seemed to have adopted a masculinist politics of centralised direction (Motta, 2013; Seppälä, 2016). For DBN Repeal, a feminist politics of care developed and retained distinctive and radical demands for legislation and delivery (Duffy, 2020) a clear example of developing collective agency within the campaign. The broad impression from our survey results was that members felt they could get as involved with decision-making as they wished and trusted the collective leadership to direct a successful campaign. This was especially true for those that identified themselves as 'late joiners'. Our clear focus upon a proximate goal (getting a 'Yes' vote for Repeal in the referendum) no doubt directed attention away from organisational matters that have often fostered dissension within feminist and other social movements (Mueller, 1995). While this may be argued for the DBN campaign, the same cannot be said for the national TFY campaign. In the months following the referendum many thoughtful reflections highlighted TFY's conservatism, failure to challenge restrictive draft legislation, and exclusion of migrant and ethnic minority, disabled and trans voices from the national campaign (Burns, 2018; Campbell, 2018; Enright, 2018). The restrictive Health (Regulation of Termination of Pregnancy) Act 2018 focused on harm reduction over agency (de Londras, 2020) and disproportionately restricts abortion access for some of those from 'the messier edges of the campaign' (Burns, 2018: n.p.), and in this respect continues the legacy of the 8th Amendment (Side, 2020).

\section{CONCLUSION}

Power and leadership are important elements of any social movement. DBN Repeal drew upon the experiences of Irish feminist activists practicing a 'politics of refusal' rather than the 'feel safe' campaign advocated by mainstream liberal feminist approaches (after de Alwis, 2009). We highlighted how, at the grassroots level, DBN established a movement that privileged horizontal relations of solidarity and inclusion, over vertical relations of domination. Examining how solidarity and inclusion worked, we noted the particular importance of an ethics of care. Relations of caring for and accepting care reinforced each other, allowing for new members to be integrated, sustaining the confidence of leaders, and modelling a way of being together that anticipated a broader communitarian ethic of caring-with. This practice of caring-with brought the group together, elicited untapped capacities from individuals, and allowed the group to incorporate learning from feminist empowering praxis. Members of the movement frequently mentioned these values when describing their positive experiences in the campaign. They also remarked upon the transformation of people through their engagement in the local group. The direction of the national campaign challenged this new-found assurance and consciousness, for TFY sought empathy with singular difficult cases rather than general support for female bodily integrity. Our feminist collectivist approach of power-with, caring-with, and power-to took DBN Repeal into a radical campaign for Choice. DBN Repeal began with this ethos, retained it, and thereby provided the confidence for our members to animate a conspicuously successful turn-out for Yes.

\section{ACKNOWLEDGEMENTS}

The authors are especially grateful to and inspired by our exceptional DBN members. We acknowledge the support of the Department of Geography, Maynooth University, for facilitating the DBN and Maynooth public engagement partnership in 2019-20. A special thanks to the Maynooth MA Geography and Final-Year Geography Feminist Methodologies students for their work in helping us with our interviews and transcriptions of DBN team leaders, and to Lorna O'Hara for collaborating with our project.

\section{REFERENCES}

Abbruzzese, T. V. and Wekerle, G. R. (2011). Gendered spaces of activism in exurbia: Politicizing an ethic of care from the household to the region. Frontiers: A Journal of Women Studies, 32(2), 140-169. https:/ / doi.org/10.5250/ fronjwomestud.32.2.0140

Allen, A. (2018). The power of feminist theory: Domination, resistance, solidarity. London: Routledge. https://doi.org/ $10.4324 / 9780429495939$

Barron, M. (2019). Learning from the 2018 together for yes campaign. Dublin: Together for Yes. Available at: https://www.togetherforyes.ie/app/uploads/2019/11/2019_TFY_Review.pdf (Accessed 19 November 2021). 
Batliwala, S. (2011). Feminist leadership for social transformation: Clearing the conceptual cloud. New Delbi: CREA [Creating Resources for Empowerment in Action]. Available at: https://www.uc.edu/content/dam/uc/ucwc/docs/ CREA.pdf (Accessed 19 November 2021).

Bunnage, L. A. (2014). Social movement engagement over the long haul: Understanding activist retention. Sociology Compass, 8(4), 433-445. https:// doi.org/10.1111/soc4.12141

Burns, E. (2018). \#10thdss: Intersectionality and the Irish abortion rights campaign of 2018. Emma Q Burns, 19 September. Available at: https://emmaqburns.com/2018/09/19/10thdss-intersectionality-and-the-irishabortion-rights-campaign-of-2018/ (Accessed 19 November 2021).

Campbell, E. (2018). My experience of the together for yes campaign. Sexual and Reproductive Health Matters, 10 October. Available at: http://www.srhm.org/news/my-experience-of-the-together-for-yes-tfy-campaign/ (Accessed 19 November 2021).

Chambers, R. (2018). Together for yes campaign takes to the doors. The Pat Kenny Show, Newstalk, 24 April 2018. Available at: https://www.newstalk.com/podcasts/highlights-from-the-pat-kenny-show/together-for-yescampaign-takes-to-the-doors (Accessed 19 November 2021).

Connolly, L. (2020). Explaining repeal: A long-term view, in K. Browne and S. Calkin (eds), After repeal: Rethinking abortion politics (pp. 36-52). London: Zed Press. https://doi.org/10.5040/9781350218284.ch-002

Cullen, P. and Korolczuk, E. (2019). Challenging abortion stigma: Framing abortion in Ireland and Poland. Sexual and Reproductive Health Matters, 27(3), 6-19. https:// doi.org/10.1080/26410397.2019.1686197

de Alwis, M. (2009). Interrogating the 'political': Feminist peace activism in Sri Lanka. Feminist Review, 91(1), 81-93. https://doi.org/10.1057/fr.2008.52

de Londras, F. (2020). 'A hope raised and then defeated'? The continuing harms of Irish abortion law. Feminist Review, 124, 33-50. https:// doi.org/10.1177/0141778919897582

Dewan, J. (2010). The practice of politics: Feminism, activism and social change in Ireland, in J. Hogan, P. F. Donnelly and B. K. O’Rourke (eds), Irish business and society: Governing, participating in the 21st century (pp. 520-536). Dublin: Gill and Macmillan.

Duffy, D. N. (2020). From feminist anarchy to decolonisation: Understanding abortion health activism before and after the Repeal of the 8th Amendment. Feminist Review, 124(1), 69-85. https://doi.org/10.1177/ 0141778919895498

Elkink, J., Farrell, D., Reidy, T. and Suiter, J. (2017). Understanding the 2015 marriage referendum in Ireland: Context, campaign, and conservative Ireland. Irish Political Studies, 32(3), 361-381. https://doi.org/10.1080/ 07907184.2016.1197209

Enright, M. (2018). 'The enemy of the good': Reflections on Ireland's new abortion legislation. Feminists@Law, 8(2), 1-12. https://doi.org/10.22024/UniKent/03/fal.658

Fischer, C. (2019). Abortion and reproduction in Ireland: Shame, nation-building and the affective politics of place. Feminist Review, 122(1), 32-48. https://doi.org/10.1177/0141778919850003

Fischer, C. (2020). Feminists redraw public and private spheres: Abortion, vulnerability, and the affective campaign to Repeal the Eighth Amendment. Signs: Journal of Women in Culture and Society, 45(4), 985-1010._https:/ /doi.org/ $10.1086 / 707999$

Fox-Genovese, E. (1991). Feminism without illusions: A critique of individualism. Chapel Hill: University of North Carolina Press.

Gordon, J. (1997). The libidinal constitution of a high-risk social movement: Affectual ties and solidarity in the Huk Rebellion 1946 to 1954. American Sociological Review, 62(1), 53-69. https:/ / doi.org/10.2307/2657452

Hall, B. (2019). Gendering resistance to right-wing populism: Black protest and a new wave of feminist activism in Poland? American Behavioral Scientist, 63(10), 1497-1515. https://doi.org/10.1177/0002764219831731

Hartsock, N. (1983). Money, sex, and power: Toward a feminist historical materialism. Boston: Northeastern University Press.

Holborow, M. (2018a). Ireland's abortion victory: Women's lives, the liberal agenda and the radical left. International Socialism, 60. Available at: https://isj.org.uk/irelands-abortion-victory/ (Accessed 19 November 2021).

Holborow, M. (2018b). Taking on the sexist system: Repeal and the fight for real change. Irish Marxist Review, 7(20), 40-47.

Hyde, C. (2018). Charisma, collectives, and commitment: Hybrid authority in radical feminist social movement organizations. Social Movement Studies, 17(4), 424-436. https://doi.org/10.1080/14742837.2018.1457519

Kasstan, B. and Crook, S. (2018). Reproductive rebellions in Britain and the Republic of Ireland: Contemporary and past abortion activism and alternative sites of care. Feminist Encounters: A Journal of Critical Studies in Culture and Politics, 2(2), 17. https://doi.org/10.20897/femenc/3885 
Kennedy, S. (2015). Ireland's handmaid's tale, in A. Quilty, S. Kennedy and C. Conlon (eds), The abortion papers Ireland: Volume 2 (pp. 275-281). Cork: Cork University Press.

McDonald, N., Antosik-Parsons, K., Till, K. E., Kearns, G. and Callan, J. (2020). Campaigning for choice: Canvassing as feminist pedagogy in Dublin Bay North, in K. Browne and S. Calkin (eds), After repeal: Rethinking abortion politics (pp. 124-143). London: Zed Press. https://doi.org/10.5040/9781350218284.ch-007

Mendéz, M. (2020). Operación araña: Reflections on how a performative intervention in Buenos Aires's subway system can help rethink feminist activism. Estudos Históricos, 33(7), 280-297. https://doi.org/10.1590/s217814942020000200004

Morris. A. D. and Staggenborg, S. (2004). Feminism and the women's movement: A global perspective, in D. A. Snow, S. A. Soule and H. Kriesi (eds), The blackwell companion to social movements (pp. 171-196). Oxford: Blackwell. https://doi.org/10.1002/9780470999103.ch25

Motta, S. C. (2013). 'We are the ones we have been waiting for': The feminization of resistance in Venezuela. Latin American Perspectives, 40(4), 35-54. https://doi.org/10.1177/0094582X13485706

Mueller, C. (1995). The organizational basis of conflict in contemporary feminism, in M. M. Ferree and P. Y. Martin (eds), Feminist organizations: Harvest of the new women's movement (pp. 263-275). Philadelphia: Temple University Press.

Naples, N. and Bojar, K. (2002). Teaching feminist activism: Strategies from the field. New York: Routledge.

O'Hara, L. (2021). Geographies of feminist activism and Berlin and Dublin: Hybrid feminist counterpublic spaces of resistance [PhD dissertation, Maynooth University].

Petray, T. (2010). 'This isn't a Black issue': Homophily and diversity in aboriginal activism. Social Movement Studies, 9(4), 411-424. https://doi.org/10.1080/14742837.2010.522309

Phillips, A. (1996). Dealing with difference: A politics of ideas or a politics of presence? in S. Benhabib (ed), Democracy and difference: Contesting the boundaries of the political (pp. 139-152). Princeton: Princeton University Press. https:// doi.org/10.1515/9780691234168-008

Pileggi, V., Holliday, J., De Santis, C., Lamarre, A., Jeffrey, N. Tetro, M. and Rice, C. (2015). Becoming scholars in an interdisciplinary, feminist learning context. Feminist Teacher, 26(1), 29-52. https://doi.org/10.5406/ femteacher.26.1.0029

Polletta, F. (2002). Freedom is an endless meeting: Democracy in American social movements. Chicago: University of Chicago Press. https://doi.org/10.7208/chicago/9780226924281.001.0001

Radford-Hill, S. (2000). Further to fly: Black women and the politics of empowerment. Minneapolis: University of Minnesota Press.

Ralph, D. (2021). 'Between a whisper and a shout': Repealing the Eighth and pro-choice Irish women's abortion testimonies. Gender, Place \& Culture, 29(2), 201-221. https:// doi.org/10.1080/0966369X.2020.1860911

Reger, J. (2012). Everywhere and nowhere: Contemporary feminism in the United States. Oxford: Oxford University Press.

Sambaraju, R., Sammon, M., Harnett, F. and Douglas, E. (2018). 'Her choice of course': Negotiating legitimacy of 'choice' in abortions rights deliberations during the 'Repeal the Eighth' movement in Ireland. Journal of Health Psychology, 23(2), 263-276. https://doi.org/10.1177/1359105317741659

Sandoval, C. (2002). Dissident globalizations, emancipatory methods, social erotics, in A. Cruz-Malavé and M. F. Manalansan IV (eds), Queer globalizations: Citizenship and the afterlife of colonialism (pp. 20-32). New York: New York University Press.

Santos, F. G. (2020). Social movements and the politics of care: Empathy, solidarity and eviction blockades. Social Movement Studies, 19(2), 125-143. https:/ / doi.org/10.1080/14742837.2019.1665504

Seppälä, T. (2016). Feminizing resistance, decolonizing solidarity: Contesting neoliberal development in the Global South. Joumal of Resistance Studies, 2(1), 12-47.

Side, K. (2020). Abortion im/mobility: Spatial consequences in the Republic of Ireland. Feminist Review, 124(1), 1531. https://doi.org/10.1177/0141778919894891

Smith, J. and Glidden, B. (2012). Occupy Pittsburgh and the challenges of participatory democracy. Social Movement Studies, 11(3-4), 288-294. https://doi.org/10.1080/14742837.2012.704182

Sutton, B. (2020). Intergenerational encounters in the struggle for abortion rights in Argentina. Women's Studies International Forum, 82(102392). https:// doi.org/10.1016/j.wsif.2020.102392

Taylor, M., Spillane, A. and Arulkumaran, S. (2020). The Irish journey: Removing the shackles of abortion restrictions in Ireland. Best Practice and Research Clinical Obstetrics and Gynaecology, 62, 36-48. https://doi.org/ 10.1016/j.bpobgyn.2019.05.011

Tronto, J. C. (1993). Moral boundaries: A political argument for an ethic of care. New York: Routledge.

Tronto, J. C. (2013). Caring democracy: Markets, equality and justice. New York: New York University Press. 
Vetter, L. C. (2010). Overview: Feminist theories of leadership, in K. O'Connor (ed), Gender and women's leadership: A reference handbook (pp. 3-10). London: SAGE. https://doi.org/10.4135/9781412979344.n1

Willis, E. (2012). No more nice girls: Countercultural essays. Minneapolis: University of Minnesota Press. https://doi.org/10.5749/minnesota/9780816680795.001.0001

Citation: Antosik-Parsons, K., Till, K. E., Kearns, G., Callan, J. and McDonald, N. (2022). Leading Change: Reproductive Rights, Empowerment and Feminist Solidarity in the Dublin Bay North Repeal the 8th Campaign. Feminist Encounters: A Journal of Critical Studies in Culture and Politics, 6(1), 06. https://doi.org/10.20897/femenc/11750

Copyright (C) 2022 by Author/s and Licensed by Lectito BV, Netherlands. This is an open access article distributed under the Creative Commons Attribution License which permits unrestricted use, distribution, and reproduction in any medium, provided the original work is properly cited. 